\title{
The prevalence of hypercholesterolemia and associated risk factors in Al-Kharj population, Saudi Arabia: a cross-sectional
} survey

Jamaan Al-Zahrani $1^{*}$, Mamdouh M. Shubair ${ }^{\circledR 0}$, Sameer Al-Ghamdi ${ }^{1}$, Abdullah A. Alrasheed ${ }^{3}$, Abdulrahman A. Alduraywish ${ }^{4}$, Fayez Saud Alreshidi ${ }^{5}$, Saeed Mastour Alshahrani ${ }^{6}$, Majid Alsalamah, Badr F. Al-Khateeb ${ }^{8}$ (D) Aljawharah Ibraheem Ashathri ${ }^{9}$, Ashraf El-Metwally ${ }^{10}{ }^{0}$ and Khaled K. Aldossari ${ }^{1}$ (0)

\begin{abstract}
Background: Hypercholesterolemia $(\mathrm{HC})$ is an important precursor to many cardiovascular, cerebrovascular, and peripheral vascular diseases. A report conducted by the American Heart Association showed the prevalence of $\mathrm{HC}$ to be $11.9 \%$, with around 28.5 million adults age $\geq 20$ years having high cholesterol levels. This study aimed to evaluate the prevalence of $\mathrm{HC}$ and its associated risk factors among the general population of Al-Kharj, Saudi Arabia.

Method: A cross-sectional study was conducted on the general population of Al-Kharj, Saudi Arabia in 2016. The representative sample consisted of 1019 individuals, who all participated on a voluntary basis. The statistical analysis was performed using SPSS version 25.
\end{abstract}

Results: The results of this study showed the prevalence of $\mathrm{HC}$ in the sample to be $12.5 \%$. There was a significant moderate positive association between increasing age and the prevalence of $\mathrm{HC}(r=0.240, P<0.0001)$. Males had a significantly higher prevalence of HC (56.7\%) compared to their female counterparts (43.3\%) $\left(X^{2}=23.093, P \leq 0.0001\right)$. BMI was positively and significantly associated with high cholesterol status. Participants in the overweight category had a significantly higher risk of $\mathrm{HC}(\mathrm{OR}=1.727 ; 95 \% \mathrm{Cl}=1.58-1.914 ; P=0.046)$. The non-obese $\left(<25 \mathrm{~kg} / \mathrm{m}^{2}\right)$ participants had an inverse significant association with the risk of hypercholesterolemia. $(\mathrm{OR}=0.411 ; 95 \% \mathrm{Cl}=0.216-0.783$; $P=0.007$ ).

Conclusion: In this population-based study, the predominant risk factors of $\mathrm{HC}$ in Al-Kharj region were being of a Saudi nationality, male, having obesity, being unemployed, and being a civilian worker. There is a clear need for future screening studies of $\mathrm{HC}$, as most previous studies have reported contradictory prevalence data (because they were conducted in different regions of KSA). Furthermore, well-designed prospective cohort studies are needed in the future to assess how the association between lifestyle behavioural factors such as dietary intake patterns and levels of physical activity may affect the relative risk of $\mathrm{HC}$ status.

Keywords: Hypercholesterolemia, Obesity, Cross-sectional, Al-kharj, Saudi arabia

\section{*Correspondence: jamaan.alzahrani@outlook.com}

${ }^{1}$ Family and Community Medicine Department, College of Medicine, Prince Sattam Bin Abdulaziz University, Al-Kharj 11942, Saudi Arabia Full list of author information is available at the end of the article

\section{Background}

Elevated blood cholesterol level better known as hypercholesterolemia $(\mathrm{HC})$ is an well-established risk factor for cardiovascular, cerebrovascular, and peripheral 
vascular diseases [1]. Hypercholesterolemia can be either due to primary (genetic or familial), or secondary (acquired) causes. Genetic mutations of the LDL receptor gene account for $85 \%$ of familial causes. Other factors include defective apolipoprotein B, proprotein convertase subtilisin/kexin type 9 gene gain-of-function mutation, LDL receptor adaptor protein mutation and polygenic HC [2-4]. Acquired causes include medical conditions which include hypothyroidism, diabetes mellitus, nephrotic syndrome, and cholestasis. Some medications such as cyclosporine and thiazide diuretics, as well as excessive intake of dietary cholesterol and smoking have been linked with increased risk of HC [1, $5,6]$.

Age is also a strong risk factor for $\mathrm{HC}$; more advanced age has been associated with higher risk of $\mathrm{HC}$ for both sexs [7-9]. In people who are in younger age groups (teenagers, young adults 18-25 years of age), $\mathrm{HC}$ can go undetected [10]. In a study by Basulaiman et al., it was reported that $65 \%$ of Saudis with HC were undiagnosed [9]. Another study reported that the prevalence of $\mathrm{HC}$ was $23.7 \%$ in the young age group [10]. There is currently a gap in the literature when it comes to $\mathrm{HC}$, as there is a very limited number of studies which include young adults $(18-25$ years of age) $[9,11,12]$. This age group seems to be at a relatively lower risk of having HC; however, according to the National Cholesterol Education Program (NCEP), adults 20 years of age and older should be screened for HC at least once every 5 years [13]. Additionally, in a surprising cross-sectional study conducted in children (9-12 years) - not even young adults-in Riyadh showed a prevalence of $\mathrm{HC}$ of $32.7 \%$ [14].

Sex is a risk factor for $\mathrm{HC}$ which requires more extensive research. While some studies reported greater numbers of $\mathrm{HC}$ among males [7, 8], other investigations have on the contrary reported higher levels in females [12, 15]. Furthermore, there were other 'unusual' factors that showed some association with $\mathrm{HC}$, including insomnia and early menopause $[16,17]$.

Globally, the prevalence of $\mathrm{HC}$ is relatively high. The World Health Organization (WHO) reported a global prevalence of $39 \%$ in 2008 [18]. Recent estimates have shown that around 28.5 million people from the adult population (aged 20 years or older) have high levels of total serum cholesterol, with the reported prevalence being $11.9 \%$ [19]. Data on HC levels in the Middle East are very limited. In a study conducted in 14 African and Middle Eastern (AFME) countries, the dyslipidemia level was as high as $70 \%$. However, the prevalence of $\mathrm{HC}$ was not mentioned [20]. In Saudi Arabia, the prevalence of $\mathrm{HC}$ ranges widely from 8.5 to $54.9 \%$ in both the general population and the stable clinic visitors in different regions of the Kingdom [11, 12, 21].
This wide range of $\mathrm{HC}$ prevalence figures could be due to the fact that $\mathrm{HC}$ is an asymptomatic condition. It could also be a result of the differences between the studied age groups, sex, ethnic heterogeneity, and many other factors. Given that studies on $\mathrm{HC}$ are scarce in the Middle East and in Saudi Arabia, there is a significant need for a thorough cross-sectional population-based study in the region. Therefore, the current study aims to provide reliable data on the prevalence of hypercholesteremia at a population level. In order to have a comprehensive view of the topic, the study investigated the relationship between hypercholesteremia and its associated factors, including age, sex, marital status, body mass index (BMI), education level, employment status, diabetes status, and smoking status.

\section{Methods}

This was a cross-sectional study conducted in Al-Kharj region of Saudi Arabia. The study's duration was six months, starting from January to June 2016. The estimated total population of the city at the time of the study was reported to be slightly over 0.3 million $(n=300,000)$. $\mathrm{Al}-\mathrm{Kharj}$ is one of the Kingdom's major hubs, having great economic importance and up-to-date administration. It also possesses significant natural resources, an important geographical location, and population diversity (a population with a variety of ethnic backgrounds). Moreover, published studies showed that among the population of Al-Kharj, the prevalence of hypertension was $30.3 \%$, the prevalence of obesity was $49.6 \%$, and the risk of coronary heart disease (CHD) was $2.5 \%$ [22]. Given the increased prevalence of these chronic conditions (hypertension, obesity, and CHD), the assessment of hypercholesterolemia and its association to certain risk factors for $\mathrm{CHD}$ in the current study is warranted.

\section{Study population}

Figure 1 represents the inclusion and exclusion criteria of the study population.

\section{Data collection procedure and tools}

A total of 1200 respondents participated in the study, with a response rate of $85 \%$. All incomplete questionnaires in which more than 5 responses were missing were excluded. In the final analysis, the data of a total of 1019 respondents were included. A multistage sampling technique was utilized for the collection of the data. Samples were selected from different governmental and private institutions through a cluster sampling technique. Afterwards, cluster lists were made, and seven clusters were randomly selected by the investigators for inclusion in the study. Another round of cluster sampling was performed on the selected cluster, and two clusters of that 


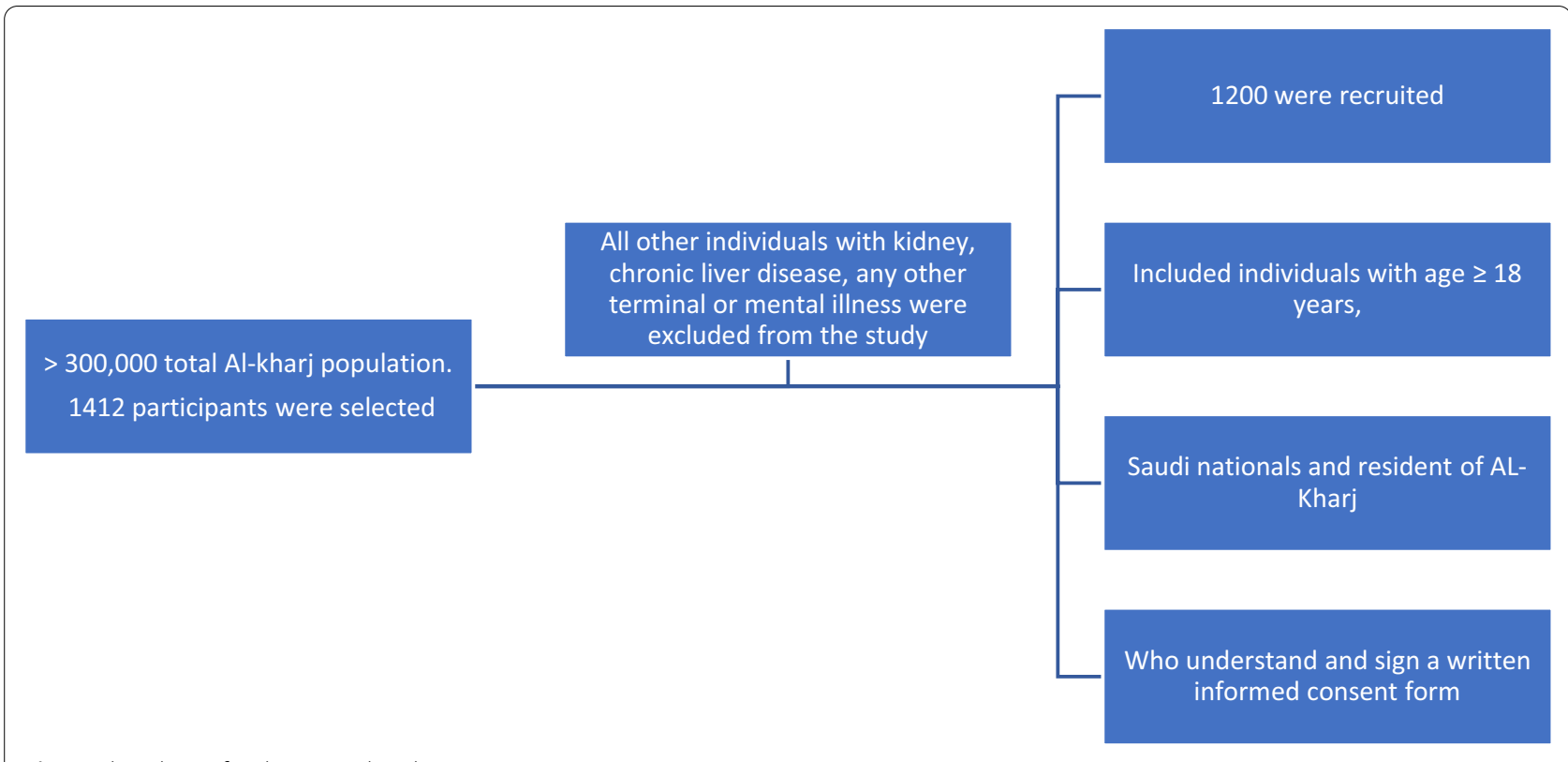

Fig. 1 Flowchart of inclusion and exclusion criteria

were then included. The total population of the selected clusters was then divided into different sampling units using the list of participants obtained from each department of the selected institutes. Study respondents were then selected using simple random sampling from each of the selected groups through a computer-generated list. Finally, the eligible subjects among them were recruited in the study. The aforementioned sample population has also been used in previously published studies [23-25].

\section{Material and measures}

Data were collected from the participants using a structured questionnaire. The questionnaire used in this study has been published previously [23, 26]. Information about sociodemographic factors such as age, sex, marital status, and education levels was obtained via the same questionnaire. Anthropometric measurements like body weight (kilograms), height (meters), Body Mass Index (BMI) and waist circumference (centimeters) were taken at the time of the interview by trained nurses. All the procedures were performed based on the standards for anthropometric measurements. In addition to this, a blood sample was drawn for a fasting (10-12 $\mathrm{h}$ fast) lipid profile from each respondent.

\section{Operational definition}

Hypercholesterolemia $(\mathrm{HC})$ is defined as a blood cholesterol level of $>200 \mathrm{mg} / \mathrm{dL}$ or $>5 \mathrm{mmol} / \mathrm{L}$ [27]. Non-obese or normal weight is defined as a BMI of $<25 \mathrm{~kg} / \mathrm{m}^{2}$, and overweight denotes a BMI of $\geq 25 \mathrm{~kg} / \mathrm{m}^{2}$, while a BMI of $\geq 30 \mathrm{~kg} / \mathrm{m}^{2}$ falls within the obese category [28].

\section{Data analyses}

Data were analyzed using SPSS version 25.0 (SPSS Inc., Chicago, Illinois, USA) for Windows. A simple chisquare test was used to examine the association between $\mathrm{HC}$ and different categorical variables. Univariate analysis was conducted using the bivariate correlation coefficient (Pearson's $r$ ), while a multinomial regression model was used to test the relationship (adjusted odds ratio) between $\mathrm{HC}$ and all other possible risk factors. The confidence interval was $95 \%$, and a $P$ value of less than 0.05 was set to establish a statistical significance.

\section{Results}

Data related to the description of the study population were previously published [23, 26]. Figure 2 shows the normal distribution (Bell curve/Histogram) of the original continuous serum cholesterol variable, with a mean of $4.63 \mathrm{mmol} / \mathrm{L}$ and a standard deviation (SD) of 0.855 for the entire sample $(n=1019)$. There were no outliers in the normal distribution of the serum cholesterol levels.

\section{Univariate analysis}

Bivariate correlation coefficient (Pearson's $r$ ) was conducted between age of respondents.

(continuous variable) and binary $\mathrm{HC}$ status $(1=$ no $\mathrm{HC}$; $2=$ yes.

hypercholesterolemia). 


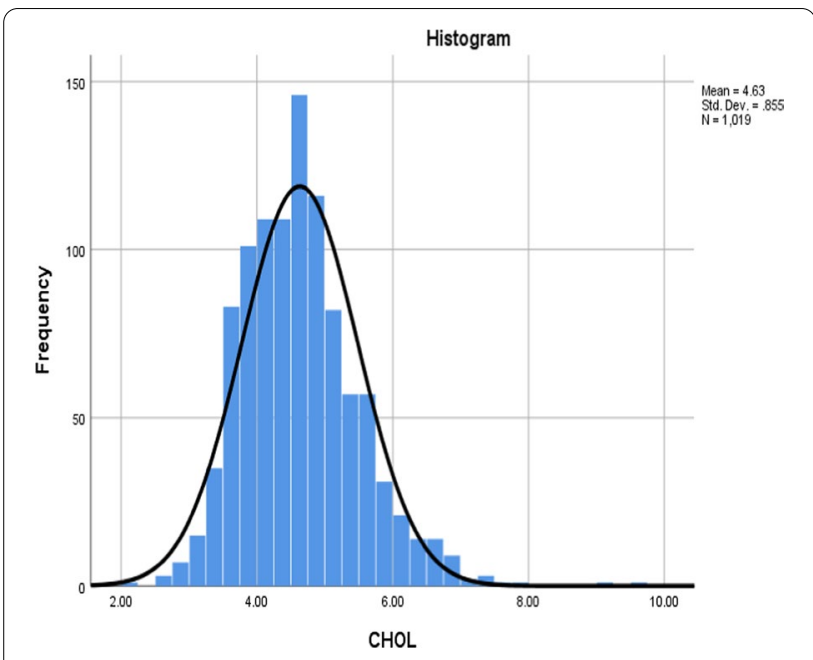

Fig. 2 Normal distribution of serum cholesterol in Al-Kharj population $(n=1019)$

The bivariate correlation coefficient (Pearson's $r$ ) was conducted between the ages of the respondents (continuous variable) and binary $\mathrm{HC}$ status $(1=$ no $\mathrm{HC} ; 2=$ yes $\mathrm{HC}$ ). The results showed that there was a significant moderate positive association between increasing age and the prevalence of $\mathrm{HC}(\mathrm{r}=0.240, P<0.0001)$. Another Pearson's $r$ correlation coefficient test revealed that a high body mass index (BMI), as a continuous variable, was positively and significantly associated with the presence of $\mathrm{HC}(\mathrm{r}=0.181, P<0.0001)$.

The prevalence of $\mathrm{HC}$ as a binary variable $(1=$ no $\mathrm{HC}$; $2=$ yes HC) was contrasted with sociodemographic and other risk factors. Seven $(n=7)$ cross-tabulation $\left(X^{2}\right)$ tests were conducted to assess the relationship between HC status and each of: sex, marital status, educational attainment, job type, diabetes status, smoking status, and body mass index (BMI) class/category.

The results are summarized in Table 1. A higher proportion of males $(56.7 \%)$ had a significantly higher prevalence of $\mathrm{HC}$ compared with their female counterparts (43.3\%). The Chi-Squared test was $\left(X^{2}\right)=23.093$, $P \leq 0.0001$. Married individuals were significantly more likely to have $\mathrm{HC}(67.7 \%)$ in comparison to individuals who had never married (32.2\%). The Chi-Squared test was $\left(X^{2}\right)=68.086, P \leq 0.0001$. When $\mathrm{HC}$ status was examined according to educational attainment, it was found that secondary school students $(23.6 \%)$ and university students $(63.8 \%)$ had the highest prevalence of HC. The Chi-Squared test was $\left(X^{2}\right)=27.177, P \leq 0.000$. In regard to job/employment type, a significant proportion of civilian workers had HC (84.3\%) compared with those who were unemployed or were soldiers. The Chi-Squared test was $\left(X^{2}\right)=56.683, P \leq 0.0001$.
The relationship between $\mathrm{HC}$ and diabetes status showed that individuals with diabetes had a higher prevalence of $\mathrm{HC}$ (91.3\%) than non-diabetic individuals with HC (8.7\%). The Chi-Squared test was $\left(X^{2}\right)=6.195$, $P=0.013$ (Table 1). There was a significant increase in the proportion of current smokers who had high cholesterol levels (15.7\%), as opposed to only $5.5 \%$ of ex-smokers who had high cholesterol levels. The Chi-Squared test was $\left(X^{2}\right)=9.044, P \leq 0.011$. Across the BMI categories, the results revealed that the overweight category showed a significantly higher proportion (33.1\%) which had high cholesterol levels, followed by the class I obese category (27.6\%), and then the class II/III obese group (18.9\%). The Chi-Squared test was $\left(X^{2}\right)=41.090, P \leq 0.0001$.

\section{Multiple logistic regression analyses}

A first multiple logistic regression analysis was conducted by using the dichotomous $\mathrm{HC}$ status (outcome variable) with BMI (continuous independent variable) and other sociodemographic and lifestyle risk factors (Table 2). The results showed that BMI was positively and significantly associated with high cholesterol status. The odds ratio (OR) was $1.64(95 \% \mathrm{CI}=1.610-1.671 ; P=0.008)$. Marital status showed a significant inverse association with $\mathrm{HC}$, in that married individuals had a significantly lower risk of having high cholesterol levels. The OR was 0.396 (95\% CI $=0.236-0.664 ; P \leq 0.0001$ ). Moreover, job type/status-whether 'not working' (unemployed) or 'civilian' - was positively and significantly associated with $\mathrm{HC}$. The OR for the 'not working' status was 3.988 (95\% $\mathrm{CI}=2.051-5.139 ; P=0.042)$, while the OR for a 'civilian' job status was 3.385 (95\% CI $=1.722-6.652 ; P \leq 0.0001)$.

A second multiple logistic regression analysis was further carried out to examine the association between BMI class (categorical variable) and the relative risk of $\mathrm{HC}$, after adjusting for sociodemographic and lifestyle risk factors (Table 3). The results showed that overweight respondents had a significantly higher risk of $\mathrm{HC}$. The odds ratio (OR) was $1.727(95 \% \mathrm{CI}=1.58-1.914$; $P=0.046)$. Non-obese $\left(<25 \mathrm{~kg} / \mathrm{m}^{2}\right)$ participants had an inverse significant association with the risk of $\mathrm{HC}$. The OR was 0.411 (95\% CI $=0.216-0.783 ; P=0.007)$. Marital status and job type/status were also significantly inversely and positively associated with $\mathrm{HC}$ respectively (Table 3).

\section{Discussion}

The study findings show that increasing age and high BMI have significant positive associations with HC. While evaluating sociodemographic and other risk factors, it was found that $\mathrm{HC}$ was significantly associated with being male, married, a university graduate, a civilian worker, diabetic, a smoker, overweight or obese. On the other hand, in the multiple regression analysis, being 
Table 1 Univariate analysis regarding HC status in the Al Kharj population sample $(n=1019)$

\begin{tabular}{|c|c|c|c|c|c|}
\hline \multirow[t]{3}{*}{ Variables } & \multicolumn{2}{|c|}{ Hypercholesterolemia } & \multirow{3}{*}{$\begin{array}{l}\text { Total } \\
(n=1019)\end{array}$} & \multirow[t]{3}{*}{ Chi-square $\left(X^{2}\right)$} & \multirow[t]{3}{*}{$P$ value } \\
\hline & No $(n=892)$ & Yes $(n=127)$ & & & \\
\hline & n (\%) & n (\%) & & & \\
\hline \multirow[t]{2}{*}{ Respondent age } & Mean (SD) & & Mean (SD) & - & - \\
\hline & 25.6 years $(8.6)$ & 31.8 years (8.6) & 26.4 years $(8.6)$ & & \\
\hline \multicolumn{6}{|l|}{ Respondent sex } \\
\hline Male & $309(34.6)$ & $72(56.7)$ & $381(37.4)$ & 23.093 & $\leq 0.0001$ \\
\hline Female & $583(65.4)$ & $55(43.3)$ & $638(62.6)$ & & \\
\hline \multicolumn{6}{|l|}{ Marital status } \\
\hline Not married & $621(69.6)$ & $41(32.3)$ & $662(65.0)$ & 68.086 & $\leq 0.0001$ \\
\hline Married & $271(30.4)$ & $86(67.7)$ & $357(35.0)$ & & \\
\hline \multicolumn{6}{|l|}{ Education level } \\
\hline Primary & $15(1.7)$ & $7(5.5)$ & $22(2.2)$ & 27.177 & $\leq 0.0001$ \\
\hline Secondary & $101(11.3)$ & $30(23.6)$ & $131(12.9)$ & & \\
\hline Intermediate & $28(3.1)$ & $2(1.6)$ & $30(2.9)$ & & \\
\hline University & $719(80.6)$ & $81(63.8)$ & $800(78.5)$ & & \\
\hline Postgraduate & $29(3.8)$ & $7(5.5)$ & $36(3.5)$ & & \\
\hline \multicolumn{6}{|l|}{ Job type } \\
\hline Not working & $28(3.1)$ & $4(3.1)$ & $32(3.1)$ & 56.683 & $\leq 0.0001$ \\
\hline Civilian & $440(49.3)$ & $107(84.3)$ & $547(53.7)$ & & \\
\hline Soldier & $424(47.5)$ & $16(12.6)$ & $440(43.2)$ & & \\
\hline \multicolumn{6}{|l|}{ Diabetes status } \\
\hline Diabetic & $858(96.2)$ & $116(91.3)$ & $974(95.6)$ & 6.195 & 0.013 \\
\hline Non-diabetic & $34(3.8)$ & $11(8.7)$ & $45(4.4)$ & & \\
\hline \multicolumn{6}{|l|}{ Smoking status } \\
\hline Non-smoker & $787(88.2)$ & $100(78.7)$ & $887(87.0)$ & 9.044 & 0.011 \\
\hline Ex-smoker & $24(2.7)$ & $7(5.5)$ & $31(3.0)$ & & \\
\hline Current smoker & $81(9.1)$ & $20(15.7)$ & $101(9.9)$ & & \\
\hline \multicolumn{6}{|l|}{ BMI class } \\
\hline Non-obese $\left(<25 \mathrm{~kg} / \mathrm{m}^{2}\right)$ & $439(49.3)$ & $26(20.5)$ & $465(45.7)$ & 41.090 & $\leq 0.0001$ \\
\hline Overweight $\left(25-29.9 \mathrm{~kg} / \mathrm{m}^{2}\right)$ & $230(25.8)$ & $42(33.1)$ & $272(26.7)$ & & \\
\hline Class I obese $\left(30-34.9 \mathrm{~kg} / \mathrm{m}^{2}\right)$ & $134(15.0)$ & $35(27.6)$ & $169(16.6)$ & & \\
\hline Class II/III obese $\left(\geq 35 \mathrm{~kg} / \mathrm{m}^{2}\right)$ & $88(9.9)$ & $24(18.9)$ & $112(11.0)$ & & \\
\hline
\end{tabular}

overweight, unemployed and being a civilian worker were significant positive predictors. Whereas non-obese $\left(<25 \mathrm{~kg} / \mathrm{m}^{2}\right)$ and married individuals had a significant inverse association with $\mathrm{HC}$.

The prevalence of $\mathrm{HC}$ in this study population is around $12.5 \%$. A recent study conducted in Al-Hofuf region showed findings that were nearly consistent with those of this analysis [15]. In previously published studies with large sample sizes, it was reported that the prevalence of $\mathrm{HC}$ was 54\% (in 2008) and 8.5\% (in 2013) among Saudis [7, 9]. However, the prevalence of $\mathrm{HC}$ varies between different populations. The prevalence of $\mathrm{HC}$ appears to be increasing over time in developing countries [29]. For instance, the reported prevalence among the Nigerian population is 38\% [30], while Taiwan has an estimated prevalence of $44 \%$ [31], and Korea reported a prevalence of $19.5 \%$ in 2015 [32]. Data from WHO's Global Health Observatory showed that $\mathrm{HC}$ was highest in Europe (54\%), followed by America (48\%), South East Asia (29\%), and Africa (22.6\%) [18].

It was found that males had a higher prevalence of $\mathrm{HC}$ than females. Likewise, a recent university survey reported that $\mathrm{HC}$ and hypertriglyceridemia were more common among males [8]. The recent Africa Middle East Cardiovascular Epidemiological (ACE) Study reported significant differences between males (81\%) and females (63\%) [20]. In a Japanese prospective cohort study, unemployed men with fewer than 
Table 2 Logistic regression model using BMI (continuous variable) as a predictor for hypercholesterolemia status (binary outcome), after adjusting for sociodemographic and other variables $(n=1019)$

\begin{tabular}{|c|c|c|c|c|c|c|}
\hline \multirow[t]{2}{*}{ Hypercholesterolemia status } & \multirow[t]{2}{*}{ B } & \multirow[t]{2}{*}{ SE of $B$} & \multirow[t]{2}{*}{$P$ value } & \multirow[t]{2}{*}{ Exp (B)/odds ratio } & \multicolumn{2}{|c|}{$95 \% \mathrm{Cl}$ for odds ratio } \\
\hline & & & & & Lower & Upper \\
\hline Body Mass Index (BMI) & 2.039 & 0.015 & 0.008 & 1.640 & 1.610 & 1.671 \\
\hline Age & 0.012 & 0.016 & 0.452 & 1.012 & 0.981 & 1.044 \\
\hline Sex (female) & -0.288 & 0.258 & 0.029 & 0.760 & 0.452 & 1.248 \\
\hline Marital status (married) & -0.926 & 0.263 & 0.0001 & 0.396 & 0.236 & 0.664 \\
\hline Education level & 0.379 & 0.671 & 0.572 & 1.461 & 0.392 & 5.440 \\
\hline Job (not working) & 1.383 & 0.681 & 0.042 & 3.988 & 2.051 & 5.139 \\
\hline Job (civilian) & 1.219 & 0.345 & 0.0001 & 3.385 & 1.722 & 6.652 \\
\hline Diabetes (yes) & 0.026 & 0.408 & 0.950 & 1.026 & 0.461 & 2.284 \\
\hline Smoking status (no) & -0.170 & 0.311 & 0.584 & 0.843 & 0.459 & 1.551 \\
\hline Smoking status (ex-smoker) & 0.188 & 0.521 & 0.719 & 1.207 & 0.434 & 3.352 \\
\hline
\end{tabular}

$\mathrm{B}=$ Beta Coefficient, $\mathrm{SE}$ of $\mathrm{B}=$ standard error of beta coefficient

Table 3 Logistic regression model using BMI class (categorical variable) as a predictor for hypercholesterolemia status (binary outcome), after adjusting for sociodemographic and other variables $(n=1019)$

\begin{tabular}{|c|c|c|c|c|c|c|}
\hline \multirow[t]{2}{*}{ Hypercholesterolemia status } & \multirow[t]{2}{*}{ B } & \multirow[t]{2}{*}{ SE of B } & \multirow[t]{2}{*}{$P$ value } & \multirow[t]{2}{*}{ Exp (B)/odds ratio } & \multicolumn{2}{|c|}{$95 \% \mathrm{Cl}$ for odds ratio } \\
\hline & & & & & Lower & Upper \\
\hline BMI class (non-obese) & -0.889 & 0.329 & 0.007 & 0.411 & 0.216 & 0.783 \\
\hline BMI class (overweight) & 1.319 & 0.973 & 0.046 & 1.727 & 1.58 & 1.914 \\
\hline Age & 0.010 & 0.016 & 0.512 & 1.010 & 0.980 & 1.042 \\
\hline Sex (female) & -0.275 & 0.258 & 0.026 & 0.759 & 0.458 & 1.259 \\
\hline Marital status (married) & -0.883 & 0.268 & 0.001 & 0.413 & 0.245 & 0.698 \\
\hline Education level & 0.447 & 0.672 & 0.506 & 1.563 & 0.419 & 5.833 \\
\hline Job (not working) & 1.394 & 0.684 & 0.042 & 4.030 & 2.054 & 5.415 \\
\hline Job (civilian) & 1.217 & 0.346 & 0.000 & 3.377 & 1.713 & 6.656 \\
\hline Diabetes (yes) & 0.042 & 0.412 & 0.920 & 1.042 & 0.465 & 2.335 \\
\hline Smoking status (no) & -0.140 & 0.312 & 0.653 & 0.869 & 0.471 & 1.602 \\
\hline Smoking status (ex-smoker) & 0.189 & 0.524 & 0.718 & 1.209 & 0.432 & 3.377 \\
\hline
\end{tabular}

$\mathrm{B}=$ beta coefficient, $\mathrm{SE}$ of $\mathrm{B}=$ standard error of beta coefficient

13 years of education had higher risk of HC [33]. However, contrasting results were found in some studies, in which $\mathrm{HC}$ was more frequently found in females [7, 30, $34]$, while other studies reported no differences in the prevalence of $\mathrm{HC}$ of both sexs [7].

Similarly, being overweight, unemployed, and being a civilian worker were positively associated with HC. Another Saudi study reported a higher prevalence of HC, with the main cause being a combination of unhealthy dietary habits and a lack of physical activity [7]. In one study, the estimated prevalence of physical inactivity was $96 \%$, which increased with age and decreased with higher education level [35]. The key drivers for these findings are urbanization and the ubiquity of unhealthy diets and processed food across the entire Kingdom of Saudi Arabia [36]. Nonetheless, one study found no association between BMI and HC [29].
Furthermore, the current study found a higher prevalence of hypercholesterolemia among diabetic participants. A recently published Berlin Aging Study II (BASEII) found that elderly individuals on lipid lowering medication had a higher prevalence of diabetes [10]. However, most published studies have reported a higher prevalence of $\mathrm{HC}$ among diabetic individuals [27, 37]. A study conducted in Jeddah among primary healthcare employees reported that diabetic participants had a significant nine-fold increased risk of developing $\mathrm{HC}$ $(\mathrm{OR}=9.27 ; 95 \% \mathrm{CI}=1.68-52.19, P=0.019)[29]$. Another Saudi study reported that the risk of having $\mathrm{HC}$ was doubled for diabetic individuals [9].

Naturally, there were few limitations to the current study. First, this was a cross-sectional study; therefore, causal inferences for observed significant associations cannot be made. Second, some risk factors were not 
explored, such as dietary habits, daily consumption of fat, physical activity/inactivity, family history, and drug/ medication history, which could all be plausible contributory factors impacting the prevalence of HC. Third, the findings of the current study cannot be generalizable to some other countries due to differences in geographic location, lifestyle factors, and medical healthcare facilities. On the other hand, the major strength of the current study is its utilization of cluster sampling techniques, which, according to WHO's recommendation, assures that the recruited sample accurately represents the entire population. The study also included common risk factors and evaluated their association with HC. Hypercholesterolemia $(\mathrm{HC})$ and $\mathrm{BMI}$ were not self-reported but were measured through blood samples, while height, weight and all other data were collected by trained staff to ensure the reliability of the data.

\section{Conclusion}

In a population-based study, the prevalence of $\mathrm{HC}$ in Saudi Arabia was found to be $12.5 \%$, which is lower than what was reported in previous studies. Regarding the predominant risk factors, it was found that being Saudi, male, having obesity, being unemployed, and being a civilian worker were factors associated with $\mathrm{HC}$ in $\mathrm{Al}-$ Kharj region. These findings indicate that many noncommunicable diseases, particularly cardiovascular disease (CVD), can be prevented by targeting high risk populations. Community-based awareness and education campaigns should be directed towards increasing individuals' knowledge of the risk factors for HC. There is also a need for more screening studies, as most of the studies conducted in different regions of KSA show different prevalence rates. Furthermore, well-designed prospective cohort studies are warranted in the future in order to assess how the relationship between dietary intake patterns and physical activity/inactivity levels my affect the risk of $\mathrm{HC}$.

\section{Acknowledgement}

Not applicable.

\section{Author's contributions}

$A A, J M A Z, K K A, A A A, M A S$ and AEM were involved in the design of the study. SG contributed to the data collection for this study. AIA and KKA wrote the first draft of the manuscript, after, AAA, FSA, AEM, KKA and BFA read and contributed to the revision of the manuscript. MMS did the statistical analysis, results, and contributed to the final revisions of the manuscript. AEM, AA, JMAZ, KKA, MAS, BFA and SMA contributed to the final revisions of the manuscript. All authors read and approved the final manuscript.

\section{Funding}

This research received no specific grant from any funding agency in the public, commercial or not-for-profit sectors.

\section{Availability of data and materials}

The data used in this study is only available upon request by the corresponding author of Prince Sattam Bin Abdulaziz University.
Ethics approval and consent to participate

Ethical approval was obtained for this study from the local Institutional Review board of College of the Medicine, Prince Sattam Bin Abdulaziz University, AlKharj, Saudi Arabia. Consent was taken both verbally and in written form after a thorough explanation of the study procedures was given to the voluntarily recruited participants. Confidentially of the study participants was carefully maintained through data de-identification.

\section{Consent to publish}

Not applicable. This manuscript did not contain any individual personal data.

\section{Competing interest}

The authors declare that they have no competing interests.

\section{Author details}

${ }^{1}$ Family and Community Medicine Department, College of Medicine, Prince Sattam Bin Abdulaziz University, Al-Kharj 11942, Saudi Arabia. ${ }^{2}$ School of Health Sciences, University of Northern British Columbia (UNBC), 3333 University Way, Prince George, BC V2N 4Z9, Canada. ${ }^{3}$ Family and Community Medicine Department, College of Medicine, King Saud University, Riyadh, Saudi Arabia. ${ }^{4}$ Internal Medicine Department, College of Medicine, Jouf University, Sakaka, Saudi Arabia. ${ }^{5}$ Family and Community Medicine Department, College of Medicine, University of Hail, Hail, Saudi Arabia. ${ }^{6}$ College of Applied Medical Sciences, King Khalid University, Abha, Saudi Arabia. ${ }^{7}$ Department of Emergency Medicine, King Abdulaziz Medical City, College of Public Health and Health Informatics, King Saud Bin Abdulaziz University for Health Sciences, Riyadh, Saudi Arabia. ${ }^{8}$ Department of Family Medicine, King Abdulaziz Medical City, College of Public Health and Health Informatics, King Saud Bin Abdulaziz University for Health Sciences, Riyadh, Saudi Arabia. ${ }^{9}$ Clinical Nutrition, Community Health Department, Applied Medical Science, King Saud University, Riyadh, Saudi Arabia. ${ }^{10}$ College of Public Health and Health Informatics, King Saud Bin Abdulaziz University for Health Sciences, Riyadh, Saudi Arabia.

Received: 3 September 2020 Accepted: 14 December 2020

Published online: 07 January 2021

\section{References}

1. Durrington P. Dyslipidaemia. Lancet (Lond, Engl). 2003;362(9385):717-31. https://doi.org/10.1016/s0140-6736(03)14234-1.

2. Dainis AM, Ashley EA. Cardiovascular precision medicine in the genomics era. JACC Basic TransI Sci. 2018;3(2):313-26.

3. Mytilinaiou M, Kyrou I, Khan M, Grammatopoulos DK, Randeva HS. Familial hypercholesterolemia: new horizons for diagnosis and effective management. Front Pharmacol. 2018;9:707.

4. Sturm AC, Knowles JW, Gidding SS, Ahmad ZS, Ahmed CD, Ballantyne CM, et al. Clinical genetic testing for familial hypercholesterolemia: JACC scientific expert panel. J Am Coll Cardiol. 2018;72(6):662-80. https://doi. org/10.1016/j.jacc.2018.05.044.

5. Liberopoulos EN, Elisaf MS. Dyslipidemia in patients with thyroid disorders. Hormones Athens. 2002;1:218-23.

6. Osser DN, Najarian DM, Dufresne RL. Olanzapine increases weight and serum triglyceride levels. J Clin Psychiatr. 1999;60(11):767-70.

7. Al-Nozha MM, Arafah MR, Al-Maatouq MA, Khalil MZ, Khan NB, Al-Marzouki K, et al. Hyperlipidemia in Saudi Arabia. Saudi Med J. 2008;29(2):282-7.

8. Al-Hassan YT, Fabella EL. Lipid profile analysis of patients in a saudi university clinic. Public Health Int. 2017;2(3):89-95.

9. Basulaiman M, El Bcheraoui C, Tuffaha M, Robinson M, Daoud F, Jaber S, et al. Hypercholesterolemia and its associated risk factors-Kingdom of Saudi Arabia, 2013. Ann Epidemiol. 2014;24(11):801-8.

10. Rosada A, Kassner U, Weidemann F, König M, Buchmann N, SteinhagenThiessen E, et al. Hyperlipidemias in elderly patients: results from the Berlin Aging Study II (BASEII), a cross-sectional study. Lipids Health Dis. 2020;19:1-10.

11. Al-nuqali E, Abaalkhail BA, Alshareef KM. Prevalence of dyslipidemia and its associated factors among employees of primary health care centers, Jeddah, Saudi Arabia. Int J. 2016;5(5):946. 
12. Al-Kaabba AF, Al-Hamdan NA, El Tahir A, Abdalla AM, Saeed AA, Hamza MA. Prevalence and correlates of dyslipidemia among adults in Saudi Arabia: results from a national survey. Open J Endocr Metab Dis. 2012;2(04):89.

13. Third Report of the National Cholesterol Education Program (NCEP) Expert Panel on Detection, Evaluation, and Treatment of High Blood Cholesterol in Adults (Adult Treatment Panel III) final report. Circulation. 2002;106(25):3143-421.

14. Al-Shehri SN, Saleh ZA, Salama MM, Hassan YM. Prevalence of hyperlipidemia among Saudi school children in Riyadh. Ann Saudi Med. 2004;24(1):6-8.

15. Al-Hassan YT, Fabella EL, Estrella E, Aatif M. Prevalence and determinants of dyslipidemia: data from a Saudi University Clinic. Open Public Health J. 2018;11(1):416-24.

16. Lee JS, Hayashi K, Mishra G, Yasui T, Kubota T, Mizunuma H. Independent association between age at natural menopause and hypercholesterolemia, hypertension, and diabetes mellitus: Japan nurses' health study. J Atheroscler Thromb. 2012;20:161-9.

17. Lin CL, Tsai YH, Yeh MC. The relationship between insomnia with short sleep duration is associated with hypercholesterolemia: a cross-sectional study. J Adv Nurs. 2016;72(2):339-47.

18. WHO global health observatory data, Raised Cholesterol. 2020 [cited 11 August 2020]. https://www.who.int/gho/ncd/risk_factors/cholestero I_text/en/.

19. Benjamin EJ, Virani SS, Callaway CW, Chamberlain AM, Chang AR, Cheng S, et al. Heart disease and stroke statistics - 2018 update: a report from the American Heart Association. Circulation. 2018;137:e67-492.

20. Raal FJ, Alsheikh-Ali AA, Omar MI, Rashed W, Hamoui O, Kane A, et al. Cardiovascular risk factor burden in Africa and the Middle East across country income categories: a post hoc analysis of the cross-sectional Africa Middle East Cardiovascular Epidemiological (ACE) study. Arch Public Health. 2018;76(1):15

21. Medani KET, Al Mansour MA, Mohamed EY, Alfhaid F, Alghamdi TS, Sami W, et al. Prevalence and risk factors of hypercholesterolemia in Majmaah Saudi Arabia. Majmaah J Health Sci. 2018;6(1):34-41.

22. Alhabib KF, Batais MA, Almigbal TH, Alshamiri MQ, Altaradi $H$, Rangarajan $S$, et al. Demographic, behavioral, and cardiovascular disease risk factors in the Saudi population: results from the Prospective Urban Rural Epidemiology study (PURE-Saudi). BMC Public Health. 2020;20(1):1213. https:// doi.org/10.1186/s12889-020-09298-W

23. Aldiab A, Shubair MM, Al-Zahrani JM, Aldossari KK, Al-Ghamdi S, Househ $\mathrm{M}$, et al. Prevalence of hypertension and prehypertension and its associated cardioembolic risk factors: a population based cross-sectional study in Alkharj, Saudi Arabia. BMC Public Health. 2018;18(1):1327.6267095. https://doi.org/10.1186/s12889-018-6216-9.

24. Al-Ghamdi S, Shubair MM, Aldiab A, Al-Zahrani JM, Aldossari KK, Househ $\mathrm{M}$, et al. Prevalence of overweight and obesity based on the body mass index: a cross-sectional study in Alkharj, Saudi Arabia. Lipids Health Dis. 2018:17(1):134.5989365. https://doi.org/10.1186/s12944-018-0778-5.

25. Aldossari KK, Aldiab A, Al-Zahrani JM, Al-Ghamdi SH, Abdelrazik M, Batais MA, et al. Prevalence of prediabetes, diabetes, and its associated risk factors among males in Saudi Arabia: a population-based survey. J Diabetes Res. 2018;2018:12. https://doi.org/10.1155/2018/2194604.

26. El-Metwally A, Shaikh Q, Aldiab A, Al-Zahrani J, Al-Ghamdi S, Alrasheed AA, et al. The prevalence of chronic pain and its associated factors among Saudi Al-Kharj population: a cross sectional study. BMC Musculoskelet Disord. 2019;20(1):177.

27. Al-Mahmood AAS, Al-Sharifi EAH, Al-Mahmood AA. Epidemiology of hypercholesterolemia among adults in Samara City. Indian J Public Health. 2020;11(01):937.

28. CDC.gov. Defining adult overweight and obesity 2020, June 22. https:// www.cdc.gov/obesity/adult/defining.html.

29. Basheikh K, Felemban AH, Felemban MH, Al-Raddadi RM, Al-nuqali E, Abaalkhail BA, et al. Prevalence of dyslipidemia and its associated factors among employees of primary health care centers, Jeddah, Saudi Arabia. Int J Med Sci Public Health. 2016;5(5):946-52.

30. Adeloye D, Abaa DQ, Owolabi EO, Ale BM, Mpazanje RG, Dewan MT, et al. Prevalence of hypercholesterolemia in Nigeria: a systematic review and meta-analysis. Public Health. 2020;178:167-78. https://doi.org/10.1016/j. puhe.2019.09.002.

31. Tsao C-F, Chang C-M, Weng S-W, Wang P-W, Lin C-Y, Lu S-N. Identifying endemic areas and estimating the prevalence of hyperlipidemia in Taiwan's townships. J Formos Med Assoc. 2020. https://doi.org/10.1016/j. ifma.2020.05.031.

32. Jeong J-S, Kwon H-S. Prevalence and clinical characteristics of dyslipidemia in Koreans. Endocrinol Metab. 2017;32(1):30-5.

33. Fujiyoshi N, Arima H, Satoh A, Ojima T, Nishi N, Okuda N, et al. Associations between socioeconomic status and the prevalence and treatment of hypercholesterolemia in a general Japanese population: NIPPON DATA2010. J Atheroscleros Thrombos. 2018:25(7):606-20.

34. Karunakaran U, Aslesh OP, Jayasree AK, Venugopalan AK, Divakaran B, Mayamol TR, et al. Prevalence of hypercholesterolaemia among adults aged over 30 years in a rural area of north Kerala, India: a cross-sectional study. WHO South-East Asia J Public Health. 2016;5(1):70-5.

35. Al-Nozha MM, Al-Hazzaa HM, Arafah MR, Al-Khadra A, Al-Mazrou YY, AlMaatouq MA, et al. Prevalence of physical activity and inactivity among Saudis aged 30-70 years. Saudi Med J. 2007;28(4):559-68.

36. Al-Hazzaa HM. Physical inactivity in Saudi Arabia revisited: a systematic review of inactivity prevalence and perceived barriers to active living. Int J Health Sci. 2018;12(6):50

37. Climent E, Pérez-Calahorra S, Benaiges D, Pintó X, Suárez-Tembra M, Plana $\mathrm{N}$, et al. Clinical and genetic differences between heterozygous familial hypercholesterolemia patients with and without type 2 diabetes. Rev Española Cardiol (Engl Ed). 2019;73:718-24.

\section{Publisher's Note}

Springer Nature remains neutral with regard to jurisdictional claims in published maps and institutional affiliations.
Ready to submit your research? Choose BMC and benefit from:

- fast, convenient online submission

- thorough peer review by experienced researchers in your field

- rapid publication on acceptance

- support for research data, including large and complex data types

- gold Open Access which fosters wider collaboration and increased citations

- maximum visibility for your research: over 100M website views per year

At BMC, research is always in progress.

Learn more biomedcentral.com/submissions 